\title{
PEMBERDAYAAN MASYARAKAT MELALUI PRAKTEK KOMUNIKASI INTERPERSONAL KEPADA GURU DI SLB BC AUTIS YAYASAN BINA ASIH
}

\section{COMMUNITY EMPOWERMENT THROUGH INTERPERSONAL COMMUNICATION PRACTISE TOWARDS TEACHERS IN SLB BC AUTIS YAYASAN BINA ASIH}

\author{
${ }^{1)}$ Dian Purworini, ${ }^{2)}$ Aprilia Ayu Savira, ${ }^{3)}$ Mar'atus Sholihah \\ ${ }^{1,2,3)}$ Program Studi Ilmu Komunikasi \\ Fakultas Komunikasi dan Informatika, Universitas Muhammadiyah Surakarta \\ Jln. A. Yani Tromol Pos 1 Pabelan, Kartasura \\ Email: dian.purworini@ums.ac.id
}

\begin{abstract}
ABSTRAK
Yayasan Bina Asih Surakarta yang memiliki siswa-siswa berkebutuhan khusus, yaitu tuna rungu, tuna wicara, tuna grahita, autis, dan anak-anak yang memiliki IQ di bawah standar. Pelatihan ini bertujuan meningkatkan pengetahuan guru dalam menerapkan keterampilan komunikasi antar pribadi kepada siswa. Metode yang digunakan adalah ceramah, diskusi, serta praktek mengajar menggambar dan mewarnai. Hasil kegiatan menunjukkan ada peningkatan keterampilan guru dalam menerapkan komunikasi interpersonal sebagai proses penyampaian materi ajar di kelas. Kedekatan personal guru membuat siswa lebih fokus dalam menyelesaikan tugas. Kegiatan ini juga membuat guru mampu mengidentifikasi kemampuan menggambar dan mewarnai siswa.
\end{abstract}

Kata kunci: Keterampilan Komunikasi; Guru; Siswa Berkebutuhan Khusus

\section{ABSTRACT}

Surakarta Bina Asih Foundation which has students with special needs, namely deaf, deaf, mentally disabled, autistic, and children who have IQs below the standard. This training aims to increase teacher knowledge in applying interpersonal communication skills to students. The method used is lectures, discussions, and teaching practices of drawing and coloring. The results of the activities show there is an increase in teacher skills in implementing interpersonal communication as a process of delivering teaching material in class. The personal closeness of the teacher makes students more focused on completing assignments. This activity also makes the teacher able to identify the ability to draw and color students.

Keywords: Teacher; Interpersonal Communication; Students With Special Needs

Submitted : 6 September 2019 Revision : 1 November 2019 Accepted : 21 Februari 2020

\section{PENDAHULUAN}

Proses belajar di kelas yang melibatkan guru dan siswa, dibutuhkan metode pembelajaran yang berbeda-beda menyesuaikan dengan berbagai kemampua siswa. Kondisi yang lebih kompleks terjadi dalam proses belajar yang melibatkan guru dan siswa yang berkebutuhan khusus atau disabilitas fisik. Disabilitas fisik memiliki definisi kehilangan sebagian atau semua fungsi tubuh. Anak-anak yang memiliki disabilitas yang sama terkadang memiliki kemampuan yang berbeda satu dengan yang lainnya (National Council of Educational Research and Training, 2014). 
Seorang guru dituntut untuk mampu mengembangkan hubungan dengan siswa, memahami dan mengetahui minat serta pengembangan siswa. Kesuksesan hubungan siswa dan guru adalah hal penting dalam usaha siswa untuk meraih kesuksesan.Mengingat tidak mudah untuk mengajar siswa dengan kebutuhan khusus, maka guru perlu memahami siswa dengan berbagai cara yang terkadang lebih variatif dibandingkan siswa biasa. Dengan demikian, guru akan lebih mudah mengerti kebutuhan siswa dan tidak hanya focus pada isi materi pelajaran semata.

Untuk mencapai pemahaman tersebut, guru sebagai salah satu praktisi, perlu mengetahui asumsi terkait disabilitas dan kompetensi komunikasi diri sendiri. Hal ini penting agar dapat memberikan dukungan optimal kepada anak-anak berkebutuhan khusus sesuai dengan kekuatan dan kebutuhan masing-masing anak (Kucharczyk, Sreckovic, \& Schultz, 2019).

Dalam pembelajaran di kelas, siswasiswa yang berkebutuhan khusus memerlukan materi yang fokus untuk pelatihan kemampuan mental. Untuk siswa-siswa yang masih berusia anak-anak, pelatihan kemampuan mental penting untuk dilakukan karena bermanfaat untuk meningkatkan relaksasi, menurunkan kecemasan, meningkatkan konsentrasi, meningkatkan kemampuan untuk mengurangi gangguan, meningkatkan kemampuan untuk mengelola stres dan meningkatkan tingkat kepercayaan diri di kalangan anak-anak (Spassiani \& Fraser-thomas, 2011).

Meskipun tidak selalu menjadi materi utama, seni juga memiliki manfaat penting bagi anak-anak yang berkebutuhan khusus. Seni dapat menjadi media untuk mengkomunikasikan perasaan dan pikiran. Guru, dengan demikian juga didorong untuk menemukan berbagai kegiatan seni sebagai media pembelajaran yang kreatif. Salah satu bentuk seni yang dapat diterapkan adalah mengambar, mewarnai atau melukis (Coleman, 2012).

Anak-anak yang berkebutuhan khusus membutuhkan pemahaman lebih dari guru di sekolah. Mereka sensitif dan over reaktif karena kelemahan mereka dalam mengelola diri mereka sendiri. Sehingga ketika guru memahami pikiran dan perasaan mereka, akan membuat anak-anak juga lebih mudah untuk mengkomunikasikan apa yang ingin mereka sampaikan. Guru perlu menguasi kemampuan sosial yang lebih untuk memahami dan merespon berbagai kompleksitas dalam kegiatan komunikasi sosial yang dilakukan oleh anak-anak yang memiliki kebutuhan khusus (Coleman, 2012).

Gaya belajar dan pola komunikasi mendorong siswa berkebutuhan khusus untuk berpartisipasi lebih di proses belajar. Belajar dengan menggambar dan mewarnai, adalah salah satu belajar yang juga mengandung unsur bermain dan bersenang-senang. Guru perlu mengumpulkan dan memiliki informasi lengkap tentang progres masing-masing siswa. Dengan mencermati ketika siswa-siswa menggambar atau mewarnai dapat menjadi salah satu sumber informasi terkait siswa berkebutuhan khusus. Guru, selanjutnya dapat mengidentifikasi minat dan bakat siswa berkebutuhan khusus dan dapat mengarahkan untuk diasah menjadi kemampuan lebih (Coleman, 2012).

Keterampilan komunikasi guru berperan penting dalam suksesnya proses belajar mengajar (Khan, Zia-ul-islam, Khan, \& Education, 2017). Selain itu, budaya sekolah dalam penyediaan dukungan untuk interaksi komunikasi juga menjadi faktor pendukung yang penting untuk dicermati (Bortoli, Balandin, Foreman, Arthur-kelly, \& Mathisen, 2012). Menurut Bortoli et al., (2012), dukungan dan hambatan untuk interaksi komunikasi dan menumbuhkan ikatan di kelas tidak mudah dan perlu usaha sistematis untuk mewujudkannya.

Iklim kelas adalah factor penting dalam mendukung terselenggaranya kegiatan belajar mengajar yang efektif. Iklim kelas meliputi proses pembelajaran dan kualitas interaksi antara guru dan siswa (Moen, Sheridan, Schumacher, \& Cheng, 2019). Kondisi dan latar belakang sekolah untuk siswa berkebutuhan khusus tentu membutuhkan sarana dan prasarana lebih untuk mendukung kesuksesan siswa. Meskipun begitu, tidak semua sekolah luar biasa mampu memiliki semua sarana dan prasarana yang lengkap dan memadai. Oleh karena itu, dibutuhkan perhatian oleh berbagai pihak untuk mendukung suksesnya proses belajar di sekolah luar biasa. Iklim kelas yang positif dapat memberikan interaksi yang melibatkan 
emosional, perilaku dan dukungan instruksi yang jelas kepada siswa.

Banyak anak-anak dengan kebutuhan khusus dan anak-anak dengan resiko tinggi membutuhkan dukungan untuk mengembangkan keterampilan mereka. Apabila anak-anak tersebut memiliki keterampilan, mereka akan mendapatkan modal yang mendukung perkembangan hidup mereka (McCollow \& Hoffman, 2019).

Ilmu Komunikasi sebagai disipilin ilmu sosial memiliki kelebihan untuk mampu mendorong sekolah luar biasa dapat berkembang optimal terutama identifikasi kemampuan minat dan bakat siswa melalui beragam cara komunikasi. Lebih lanjut, menyadari potensi ini kemudian mendorong dosen dan mahasiswa untuk ikut berkontribusi dalam program pengabdian yang fokus pada guru dan siswa berkebutuhan khusus.

SLB BC Autis Yayasan Bina Asih menerima siswa yang berkebutuhan yaitu tuna rungu, tuna wicara, tuna grahita, autis, dan anak-anak yang memiliki IQ di bawah standar. Sekolah ini menempati bangunan bekas sekolah yang telah dikosongkan selama 3 tahun karena lokasi sebelumnya digusur.Kondisi sarana dan prasarana masih minim sehingga tidak mengherankan jika identifikasi potensi siswa siswa di sekolah ini juga terbatas.

Pengenalan potensi siswa berkebutuhan khusus di bidang menggambar belum banyak digali dan dioptimalkan. Dengan jumlah siswa yang tiap tahun bertambah, perlu adanya cara untuk mengidentifikasi potensi menggambar siswa untuk kemudian didorong tampil dalam kegiatan kompetisi untuk semakin meningkatkan karya mereka.

Adapun siswa-siswa yang berkebutuhan khusus di sekolah ini tidak semuanya berasal dari keluarga dengan ekonomi menengah atau menengah keatas. Selain itu, latar belakang pendidikan orang tua juga tidak semuanya mampu memahami kebutuhan dan potensi anak. Oleh karena itu, perlu adanya dukungan dari pihak lain untuk menfasilitasi guru dan siswa di SLB ini untuk mengidentifikasi potensi menggambar dan mendukung ekspresi diri siswa melalui kegiatan menggambar dan mewarnai.

Berdasarkan hasil wawancara yang dilakukan terhadap kepala sekolah dan guru di SLB BC Autis Yayasan Bina Asih, maka dapat dirumuskan permasalahan yang dihadapi mitra yaitu kurangnya metode pembelajaran yang mampu mengidentifikasi potensi menggambar siswa berkebutuhan khusus.

Untuk mengatasi permasalahan yang ada, maka diperlukan upaya untuk mendampingi dan mengajarkan menggambar dan mewarnai bagi siswa berkebutuhan khusus. Pendampingan ini diperlukan agar guru dapat mengidentifikasi minat dan bakat siswa. Selain itu, siswa juga mampu menunjukkan potensi mereka dan sekaligus memiliki sarana untuk mengekspresikan perasaan mereka melalui kegiatan positif.

Tujuan dilaksanakan pengabdian masyarakat ini adalah untuk meningkatkan pengetahuan guru-guru dalam menerapkan keterampilan komunikasi antar pribadi dengan siswa-siswa berkebutuhan khusus serta mampu mengidentifikasi minat bakat siswa-siswa di bidang menggambar dan mewarnai.

\section{METODE}

Metode pelaksanaan kegiatan ini adalah ceramah, diskusi dan praktek komunikasi antar pribadi dengan siswa-siswa berkebutuhan khusus di SLB BC Autis Yayasan Bina Asih. Guru-guru yang terlibat dalam kegiatan ini berjumlah 4 orang dan dengan pengawasan dari Kepala Sekolah.

Alasan memilih sekolah luar biasa $\mathrm{AB}$ Autis Yayasan Bina Asih ini adalah karena sekolah ini adalah sekolah swasta yang rata-rata memiliki siswa berasal dari keluarga dengan ekonomi menengah ke bawah. Adapun guruguru di sekolah ini juga belum semuanya pernah mendapatkan materi tentang komunikasi antar pribadi. Sekolah ini menempati bangunan bekas sehingga memiliki keterbatasan dalam fasilitas belajar mengajar. Berikut ini tahapan kegiatan :

Tahap I: Persiapan

Tahap persiapan meliputi tahap presurvei untuk menentukan lokasi pengabdian masyarakat. Tim pelaksana mendatangi sekolah luarbiasa $A B$ Autis di Yayasan Bina Asih untuk mencari informasi terkait bagaimana proses belajar mengajar di sekolah ini. Setelah berdiskusi dengan guru dan kepala sekolah, maka ditemukan permasalahan yang dihadapi oleh guru. 
Pada tahap ini, tim pengabdian juga mendiskusikan dengan guru dan kepala sekolah bagaimana pelaksanaan pengabdian, siapa guru yang akan mendampingi dan bahan atau media ajar apa saja yang diperlukan.

Kemudian ditentukan bahwa guru yang akan mendampingi di lapangan ada 4 guru. Adapun untuk praktek skill komunikasi antar pribadi, difasilitasi dengan kegiatan menggambar dan mewarnai siswa-siswa berkebutuhan khusus. Bahan yang dibutuhkan untuk proses menggambar dan mewarnai yaitu buku notes untuk catatan, pensil joyko, lem, pastel minyak untuk mewarnai, buku gambar A3.

Dengan karakteristik siswa, tidak memungkinkan jika kegiatan dilakukan dalam waktu 1 jam, oleh karena itu, mereka diberi waktu yang menyesuaikan dengan kondisi di lapangan.

Tahap II: Penyediaan alat gambar dan mewarnai yang sesuai dengan usia mereka.

Pada tahap ini tim pengabdian membawakan peralatan dan kemudian dibagikan kepada siswa. Kelas dibuat lesehan agar siswa lebih mudah untuk menggambar dan mewarnai dengan tetap berada dekat dengan teman-temannya. Setiap guru mengawasi 6 siswa.

Tahap III: Pelaksanaan kegiatan.

Kegiatan dimulai dengan sharing kepada guru-guru terkait tema komunikasi antar pribadi. Tidak mengherankan jika guruguru terlihat antusias karena pada dasarnya untuk mampu mengajar siswa-siswa berkebutuhan khusus dibutuhkan kesabaran dan ketelatenan tersendiri. Oleh karena itu, materi komunikasi antar pribadi tidak sulit untuk dipahami oleh guru.

Dalam prakteknya untuk mengarahkan siswa-siswa dalam kegiatan mewarnai dan menggambar, ternyata tidak semudah perkiraan. Siswa -siswa diberikan peralatan dan mulai mengerjakan sesuai instruksi di karpet yang ada di kelas. Siswa -siswa sebagian tampak sudah tidak fokus dan melakukan kegiatan lain, termasuk mengajak bercanda tim pengabdian, merajuk ke guru-guru dsb.

Guru harus berkali-kali mengajak siswa untuk kembali duduk dan mengerjakan tugasnya. Tim pengabdian juga membantu dan mengajak siswa untuk menyelesaikan tugas.

Salah satu usaha yang berhasil membuat sebagian siswa mampu bertahan mengerjakan tugas adalah ketika guru dan tim pengabdian terlibat aktif dan mengajak komunikasi siswa secara personal atau satu per satu. Termasuk juga ikut memilihkan warna crayon, menunjukkan bagian yang diwarnai sebelah mana dll. Intensitas yang dekat dengan siswa ini yang membuat siswa lebih merasa nyaman sehingga menurut dengan instruksi guru.

Kegiatan ini menunjukkan bahwa guruguru di sekolah luar biasa BC Autis di Yayasan Bina Asih adalah guru-guru yang memang memiliki kepeduliaan tinggi terhadap anak didik mereka.

\section{HASIL DAN PEMBAHASAN}

Pelaksanaan kegiatan di sekolah luar biasa BC Autis di Yayasan Bina Asih memberikan hasil yang positif bagi guru di sekolah tersebut.

Sebelum ada pelaksanaan kegiatan pengabdian masyarakat, guru-guru di sekolah tersebut hanya fokus pada materi pelajaran yang selama ini sudah ada di kurikulum sekolah.

Guru sudah mengajar siswa dengan menggunakan kesabaran dan tanggung-jawab profesionalisme sebagai pendidik. Meskipun begitu, mereka belum banyak mengerti tentang konsep komunikasi antar pribadi. Oleh karena itu, kedatangan tim pengabdian dari prodi Ilmu Komunikasi disambut dengan tangan terbuka.

Berdasarkan diskusi dengan tim pengabdian, kepala sekolah mengerti bahwa kerjasama seperti ini juga dapat bermanfaat bagi siswa-siswa. Ditambah lagi, konsep komunikasi antar pribadi sebenarnya sudah dipraktekkan oleh guru-guru terhadap siswasiswa, hanya saja belum mengenal konsepkonsep dalam tema komunikasi antar pribadi.

Melalui praktek skill komunikasi antar pribadi guru dan siswa dalam kegiatan menggambar dan mewarnai, guru-guru semakin menyadari pentingnya komunikasi antar pribadi. Guru-guru juga mengakui bahwa kedekatan dan intensitas guru dapat membuat siswa berkebutuhan khusus semakin mudah untuk diarahkan. 
Selanjutnya, guru-guru berencana untuk terus meningkatkan keterampilan komunikasi antar pribadi. Hambatan yang muncul yaitu bahwa untuk sekolah luar biasa dengan target pasar menengah dan menengah ke bawah seperti ini, cukup sulit untuk menjadikan rasio guru : siswa-siswa semakin ideal.

Setelah kegiatan menggambar dan mewarnai dilakukan,tim dan guru memilih mana gambar -gambar yang dinilai baik untuk dipajang di kelas. Hal ini dilakukan untuk memberikan motivasi kepada siswa -siswa dan orang tua siswa bahwa kemampuan anak berkebutuhan khusus juga dapat ditingkatkan melalui berbagai cara salah satunya adalah menggambar dan mewarnai. Selain itu, guruguru juga mampu mencermati nama siswasiswa yang perlu dikembangkan minat dan bakatnya dalam menggambar dan mewarnai.

Penelitian menemukan fakta jika berpartisipasi dalam kegiatan seni dapat mengurangi tingkat stres. Meskipun begitu, banyak sekolah yang tidak banyak menggunakan aktivitas ini baik karena kondisi keuangan atau kebijakan tertentu. Siswa sebenarnya dapat didorong agar lebih banyak terlibat dalam kegiatan seni untuk mengurangi tingkat stres dalam keseharian mereka (Scott, 2017).

Kondisi yang terjadi di SLB BC Autis Yayasan Bina Asih juga memiliki kemiripan dengan penjelasan Scott. Sekolah ini memiliki keterbatasan keuangan dan siswa berkebutuhan khusus juga tidak semuanya memiliki latar belakang ekonomi yang cukup. Maka dari itu, memberikan perlengkapan untuk mewarnai dan menggambar dengan pensil warna dan cryon memberikan kebahagiaan tersendiri bagi siswa dan guru.

Kegiatan mewarnai ternyata tidak hanya sekedar aktivitas menyenangkan bagi siswa, tetapi kegiatan mewarnai buku dan menggunakan berbagai bentuk (termasuk bentuk lingkaran dll) telah terbukti dapat mengurangi stres dan kegelisahan, meningkatkan mood dalam terapi menggunakan seni (Mantzios \& Giannou, 2018).

Temuan ini penting untuk dipahami oleh guru-guru, terutama oleh guru yang memiliki siswa berkebutuhan khusus. Tidak semua pelajaran yang diberikan oleh guru untuk tujuan meningkatkan pengetahuan, tetapi juga dapat digunakan untuk meningkatkan kualitas psikologis dari siswa.Selain itu, juga untuk mengidentifikasi bakat siswa berkebutuhan khusus untuk memberikan kesempatan berprestasi tidak hanya di sekolah, tetapi juga mengikuti perlombaan di luar sekolah.

Kegiatan mendampingi siswa berkebutuhan khusus sangat penting dilakukan oleh guru yang memiliki skill komunikasi. Penelitian yang dilakukan oleh Khan, Zia-ulislam, Khan, \& Education(2017) terhadap 418 responden di 14 universitas di Pakistan menemukan fakta bahwa skill komunikasi guru memiliki peran penting dalam peningkatan prestasi akademik siswa. Hasil ini semakin menunjukkan jika komunikasi penting untuk dikuasai oleh guru-guru. Dalam prakteknya, banyak sekali ditemui guru-guru yang memiliki kedekatan dengan siswa, dan ini merupakan bentuk nyata dari penguasaan komunikasi oleh guru. Guru dalam mendidik tidak sekedar fokus pada materi ajar, tetapi menggunakan komunikasi, baik verbal maupun non verbal yang mampu menggugah perasaan dan pikiran dari siswa.

Proses belajar mengajar adalah seni dari komunikasi. oleh karena itu, dibutuhkan pelatihan khusus untuk guru-guru agar semakin mampu menerapkan gaya mengajar yang berkontribusi membangun skill komunikasi dengan siswa (Muste, 2016). Adapun pelatihan yang dapat dilakukan antara lain mengikuti kelas-kelas komunikasi tertentu dan kemudian praktek di sekolah dengan tema tertentu tersebut.

Prodi Ilmu Komunikasi memiliki mata kuliah yang mengajarkan tema komunikasi verbal dan non verbal, psikologi komunikasi, komunikasi interpersonal dll. Mata kuliah ini memiliki bahasan yang dapat dimanfaatkan oleh guru-guru untuk meningkatkan skill komunikasi. Dengan diskusi antara dosen dan guru, dapat mengungkap permasalahan yang dihadapi guru dalam menghadapi siswa dan menemukan solusi melalui berbagai beragam kajian konseptual dan hasil penelitian yang relevan dengan permasalahan.

Mohd \& Halim (2014) dalam observasi yang dilakukan terhadap guru dan siswa di kelas, menemukan fakta jika skill komunikasi penting digunakan dalam memberikan materi di kelas. Misalnya ketika guru menjelaskan materi, tidak harus banyak waktu untuk fokus 
pada materi bacaan melainkan justru menggunakan kontak mata untuk mendapatkan respon langsung dari siswa ataupun menunjukkan ekspresi mimik wajah ketika memberikan penjelasan terkait hal baru atau mengejutkan dll.

Penelitian Mohd \& Halim, juga dikuatkan dengan penelitian yang dilakukan oleh Duta, Panisoara, \& Panisoara (2015). Dalam penelitian mereka terhadap 245guru dari 4 universitas di Romania menemukan jika proses mengajar dan belajar terjadi jika ada komunikasi. Oleh karena itu, jika guru memiliki skill komunikasi yang bagus, akan semakin mampu menciptakan suasana belajar yang baik bagi siswa. Guru tidak hanya fokus ke materi tetapi juga memberikan kemampuan untuk mempengaruhi siswa dan meningkatkan motivasi siswa. Dengan adanya suasana kelas yang menyenangkan, siswa lebih mudah untuk menyerap apa yang diajarkan oleh guru.

Dari hasil pelaksanaan pengabdian masyarakat di SLB BC Autis Yayasan Bina Asih, dapat dijelaskan jika guru-guru di sekolah juga memerlukan pelatihan lebih yang berwujud training atau diskusi lebih lanjut dengan materi peningkatan skill komunikasi. Hal ini selaras dengan apa yang ditemukan oleh Bambaeeroo \& Shokrpour (2017) bahwa jika guru-guru praktek komunikasi, termasuk utamanya non verbal akan semakin meningkatkan kualitas penyampaian pesan kepada siswa. Komunikasi non verbal, jika diterapkan pada siswa yang perlu komunikasi dengan pesan non verbal, akan semakin membuat siswa mudah memahami karena mengerti emosi dan reaksi yang ditunjukkan oleh guru.

Penggunaan komunikasi yang efektif dapat meningkatkan kualitas hidup terutama bagi siswa berkebutuhan khusus, oleh karena itu kegiatan pengabdian seperti ini sangat diterima oleh guru-guru di sekolah khusus.

Dengan mendukung peningkatan sumber daya manusia di sekolah luar biasa AB Autis di Yayasan Bina Asih Surakarta, diharapkan dapat mendukung membangunan manusia dan daya saing bangsa terutama bagi sekolah untuk siswa berkebutuhan khusus yang datang dari keluarga sederhana.

Diharapkan dengan skill komunikasi interpersonal guru yang positif, dapat meningkatkan potensi siswa-siswa berkebutuhan khusus. Potensi tidak hanya untuk meningkatkan bakat menggambar dan mewarnai saja, tetapi juga minat melakukan kegiatan tersebut untuk media terapi bagi psikologis siswa berkebutuhan khusus.

\section{SIMPULAN}

Pelaksanaan kegiatan pengabdian masyarakat berjalan dengan baik meskipun ada beberapa kendala kecil. Guru-guru memiliki kesempatan untuk praktek keterampilan komunikasi antar pribadi dengan pendampingan tim pengabdian melalui praktek mengajar kegiatan menggambar dan mewarnai siswa-siswa.

Selain itu, dari kegiatan ini pula, guruguru mampu mengidentifikasi minat dan bakat siswa dalam bidang menggambar dan mewarnai. Serta juga mampu mengarahkan kegiatan ini untuk menjadi sarana mengekspresikan perasaan siswa-siswa berkebutuhan khusus. Guru-guru juga semakin memahami jika skill komunikasi mereka adalah faktor penting dalam suksesnya pembelajaran siswa.

Ke depan, kegiatan pengabdian perlu ditindak lanjuti melalui focus group discussion antara guru-guru dan dosen yang memiliki kompetensi mata kuliah yang mendukung skill komunikasi. Hal ini dilakukan agar lebih jelas memberikan rekomendasi kepada guru-guru terkait merumuskan metode pembelajaran di kelas yang lebih efektif dalam mengembangkan minat dan bakat siswa.

\section{UCAPAN TERIMA KASIH}

Tim pengabdian mengucapkan terimakasih kepada kepala sekolah dan guru di sekolah sekolah luar biasa BC Autis di Yayasan Bina Asih Surakarta

\section{DAFTAR PUSTAKA}

Bambaeeroo, F., \& Shokrpour, N. (2017). The impact of the teachers' non-verbal communication on success in teaching. Journal of Advances in Medical Education \& Professionalism, 5(2), 5159.

Bortoli, T. De, Balandin, S., Foreman, P., Arthur-kelly, M., \& Mathisen, B. (2012). 
Mainstream Teachers Experiences of Communicating with Students with Multiple and Severe Disabilities. Education and Training in Autism and Developmental Disabilities, 47(June), 236-252.

Coleman, M. B. (2012). Technology Spotlight : Art Adaptations for Students with Physical Disabilities. Newsletter of the Division for Physical and Health Disabilities, 30(2), 14-22.

Duta, N., Panisoara, G., \& Panisoara, I. (2015). The Effective Communication in Teaching. Diagnostic study regarding the academic learning motivation to students. Procedia - Social and Behavioral Sciences, 186 (Mei), 1007-1012

Khan, A., Zia-ul-islam, S., Khan, M., \& Education, P. (2017). Communication Skills of a Teacher and Its Role in the Development of the Students 'Academic Success. Journal of Education and Practice, 8(1), 18-21.

Kucharczyk, S., Sreckovic, M. A., \& Schultz, T. R. (2019). Practical Strategies to Promote Reflective Practice When Working with Young Children with and At-Risk for Disabilities. Early Childhood Education Journal, 47(3), 343-352. https://doi.org/10.1007/s10643-01900932-w

Mantzios, M., \& Giannou, K. (2018). When Did Coloring Books Become Mindful? Exploring the Effectiveness of a Novel Method of Mindfulness-Guided Instructions for Coloring Books to Increase Mindfulness and Decrease Anxiety. Frontiers in Psychology,
9(January), 1-9.

McCollow, M. M., \& Hoffman, H. H. (2019). Supporting Social Development in Young Children with Disabilities: Building a Practitioner's Toolkit. Early Childhood Education Journal, 47(3), 309-320. h

Moen, A. L., Sheridan, S. M., Schumacher, R. E., \& Cheng, K. C. (2019). Early Childhood Student-Teacher Relationships: What is the Role of Classroom Climate for Children Who are Disadvantaged? Early Childhood Education Journal, 47(3), 331-341. https://doi.org/10.1007/s10643-01900931-x

Yusof, F.M., \& Halim, H. (2014). Understanding Teacher Communication Skills. Procedia - Social and Behavioral Sciences 155, 471-476.

Muste, D. (2016). The Role of Communication Skills in Teaching Process. In The European Proceedings of Social \& Behavioural Sciences (pp. 1-5).

National Council of Educational Research and Training. (2014). Including Children With Special Needs.

Scott, B. A. (2017). Art as a Stress Reduction Tool. Marietta College.

Spassiani, N. A., \& Fraser-thomas, J. L. (2011). Integrating Mental Skills into a Physical Activity Program for Children and Adolescents with Intellectual Disabilities. PHEnex Journal, 3(3), 1-20. 